\title{
ASÍ NOS MUESTRAN, ¿ASÍ SOMOS?
}

\author{
Fernández García, Cristina \\ DUE. Diplomado en Enfermería \\ Pérez López, $\mathbf{M}^{\mathbf{a}}$ Lorena \\ DUE. Diplomado en Enfermería
}

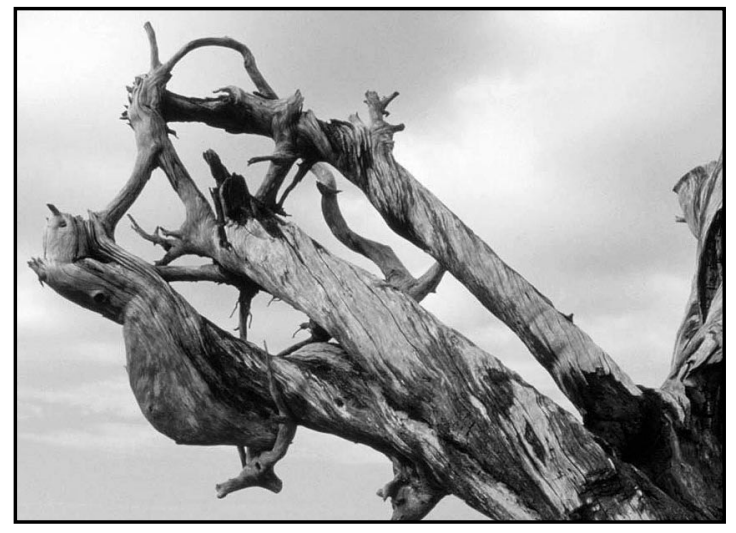

HOW WE ARE PORTRAYED, IS THAT WHAT WE ARE?

\section{SUMMARY}

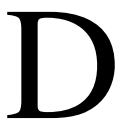

escriptive study using literature and digital material as sources, its aim is to analyse the perception society has of nursing and the role nurses play in daily life.

The scarce impact of our profession as authors of dissemination articles in the field of Health Education is a fact. So is the romantic or frivolous view of Nursing that current literature and mass media offer, as a reflection of common public opinion. Woman.

Key words: Nursing, Care, Health, Nutrition,

\section{RESUMEN}

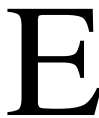

studio descriptivo que utiliza como fuente de datos material bibliográfico y digital.

Tiene por objeto analizar la visión que de la enfermería tiene la sociedad y el papel desarrollado por la profesión enfermera en el ámbito cotidiano.

Se constata el escaso impacto de nuestra profesión como autora de artículos de difusión popular en el ámbito de la Educación para la Salud, así como la visión romántica o frívola que la literatura contemporánea y los medios de comunicación ofrecen de la enfermería, como reflejo de una opinión pública muy extendida.

Palabras-clave: Enfermería, Cuidados, Salud, Nutrición, Mujer.

\section{INTRODUCCIÓN}

En la actualidad, la enfermería está llegando al final de un largo camino para alcanzar su pleno desarrollo como profesión autónoma, miembro más del equipo multidisciplinar en el que desarrolla su labor, en respuesta a una demanda de los profesionales y a una necesidad de la sociedad.

Ahora bien, ¿es la sociedad consciente de dicha necesidad? Porque ese grado de consciencia va a determinar su aceptación del nuevo rol y una justa valoración del mismo.

En nuestro medio es frecuente oír quejas sobre nuestro papel en la sombra y el tratamiento que del mismo hacen los medios de comunicación. No los podemos dejar de lado, puesto que entre ellos y la sociedad se establece una relación de influencia mutua: Los medios muestran el opinar de la sociedad y, al mismo tiempo, son los mayores modificadores de opiniones.

Ésta es la razón del presente trabajo. Ver qué papel se otorga a la enfermería desde la literatura, Internet y la prensa escrita.

\section{METODOLOGÍA}

El presente trabajo es un estudio descriptivo ya que las fuentes utilizadas para la realización del mismo han sido bibliográficas y digitales (libros, revistas, Internet y televisión)

Ésta búsqueda tiene por objeto analizar, desde una perspectiva general, la visión que de la profesión enfermera tiene la sociedad y el papel que la 
enfermería desarrolla en el ámbito cotidiano.

Con este propósito, se han seleccionado dos libros de literatura contemporánea: "El Clan del Oso Cavernario" y "El paciente inglés"; se han consultado diferentes páginas web: www.hotmail.com, www.terra.es, www.lycos.com, www.saludalia.com, se han revisado distintas revistas de tirada nacional y gran difusión popular entre las que destacan "Mujer de hoy","Hola", "Pronto", y se han analizado programas y series televisivas como "El show de Benny Hill", "Cruz y Raya" o "Médico de familia".

\section{RESULTADOS}

\section{* LITERATURA}

Queríamos conocer cómo ven a las enfermeras los autores actuales, aún cuando sus novelas estén ambientadas en otra época. Se leyeron 2 novelas: "El Clan del Oso Cavernario" y el conocidísimo "El paciente inglés". La primera, ambientada en una época lejana y completamente distinta a la nuestra, no distinguen la medicina de la enfermería.

El Clan del Oso Cavernario. La trama del libro se desarrolla en la Prehistoria. Partiendo de este hecho, se entiende que sobre una misma persona recayeran las tareas de médico, matrona, enfermera, farmacéutica e intermediaria de los espíritus: la curandera. Ésta pertenecía a una saga de curanderas, los conocimientos pasaban de madres a hijos impresos en los genes y sólo era preciso un pequeño recuerdo para que todo el conocimiento acumulado por sus antecesoras pasara a la nueva generación. En el libro se describen numerosos remedios naturales contra diferentes males y tratan a la enfermedad como una "manifestación misteriosa de la guerra entre los espíritus".

En lo referente a su labor enfermera, la curandera se encarga del cuidado de la embarazada, la asiste en el parto y puerperio y le facilita la ayuda en su ciclo como mujer. Asegura la alimentación de bebés y enfermos, facilitándoles la preparación de alimentos más adecuada para cada situación. Alivia dolores, propicia descanso y acompaña siempre al paciente en sus sufrimientos.

El paciente inglés. Esta novela sí muestra en exclusiva nuestra profesión. Ya desde la primera página encontramos a Hana, la enfermera protago- nista, realizando labores propias de enfermería:

- Cura de las heridas por quemadura del protagonista.

- Alimentación de enfermos.

- Administración de medicamentos (analgesia)

- Procura y mantiene un entorno adecuado.

Según avanza la narración, se nos da a conocer la experiencia de Hana como enfermera de guerra a través de sus recuerdos y sentimientos. Y aquí es donde encontramos lo interesante.

"La enfermera y el paciente se habían negado a marcharse... La enfermera decía que aquel hombre estaba demasiado enfermo para trasladarlo" (Pág 32)

Nuestro código deontológico recoge la obligación de procurar lo mejor para nuestro paciente. Asistimos aquí al uso de cierta autonomía en defensa del paciente y lo que ella considera más adecuado para él, quedarse en la villa abandonada y usada como hospital de guerra.

"Ni su carácter ni su pasado le habían preparado para ser enfermera” (Pág. 53)

Lo recoge la propia OMS, la necesidad de una formación y adquisición de conocimientos y habilidades necesarios para desarrollar nuestra labor. Ahora bien, para nuestro trabajo también hace falta un talante y una personalidad adecuadas, puesto que, posiblemente, sea la nuestra la más humana de todas las profesiones científicas, además de ser testigos de muchas situaciones relacionadas con la enfermedad y la muerte que no son precisamente agradables.

“Ahora conozco la muerte... Sé como hacerles olvidar la agonía, cuando ponerles una rápida inyección de morfina... Todo puñetero general debería haber pasado por mi trabajo. Todo puñetero general. Debería haber sido el requisito previo para dar la orden de cruzar el río. ¿Quién demonios éramos nosotras para que se nos encomendara aquella responsabilidad? ¿Para que se esperase que tuviéramos el saber de sacerdotes ancianos para guiarlos hacia algo que ninguno deseaba y en cierto modo consolarlos?” (Pág. 85) 
"Los cuidados eran breves. El contrato sólo era válido hasta la muerte”. (Pág. 53)

Si bien nuestro trabajo se orienta a la prevención y la recuperación de la salud, no siempre el desenlace es el deseado, teniendo que llevar a cabo una serie de cuidados que ayuden "al buen morir". Y no sólo en el plano físico, sino también en el espiritual. ¡Cuanta tranquilidad puede dar una caricia o el coger de la mano a alguien!

A pesar de ciertos errores (llega a confundir el concepto de vena y arteria) y del tono romántico y poético de la novela, se puede apreciar que el autor se informó con precisión sobre el trabajo de una enfermera.

\section{* INTERNET}

No podíamos dejar de lado el gran intercambiador de información de nuestra época, Internet.

Procedimos a buscar páginas relacionadas con el presente tema, encontrándonos con dos situaciones: páginas de salud (www.saludalia.com) y páginas de enfermería (desde el buscador de Lycos)

- Saludalia.com.- Página dedicada a la salud, con presentación atractiva y contenidos asequibles al público en general.

Analizados los contenidos de la página que pueden tener relación con la profesión enfermera y las actuaciones propias de la misma, principalmente la educación para la salud en diversos ámbitos, se ha observado que gran parte de los artículos y monografías no son firmados por nadie en particular (la redacción a lo sumo), y otra parte es firmada por diversos especialistas médicos. Ejemplos de ello son los artículos "Altibajos de los carbohidratos: ¿cómo afectan los alimentos a los niveles de azúcar en sangre?"; "El estreñimiento: un problema frecuente"; "Ejercicio físico y Diabetes Mellitus".

- El buscador Lycos nos derivó a un buen número de páginas de enfermería para enfermería, ninguna de ellas iba destinada al público en general.

\section{* TELEVISIÓN}

Se quiso tratar este medio de comunicación, pero la falta de tiempo impidió poder desarrollarlo. Solamente señalar que nuestro colectivo es un recurso fácil para rellenar escenas y tramas. Basta recordar a "Gertru", única enfermera del Centro de Salud donde trabajaba Nacho, protagonista de Médico de Familia, que tantas cartas airadas provocó por su atuendo. Curiosamente, y según avanzaba la serie, apenas se oyeron quejas por el escaso trabajo que desarrollaba, ocupada en tomar café y siendo la "consejera" de Emilio Aragón.

Cambiando de escenario, no olvidemos las eróticas enfermeras con que diversos humoristas regalan la vista a sus espectadores.

\section{* REVISTAS}

La mayoría de las revistas ofrecen páginas de salud. Estas páginas suelen estar firmadas por médicos, pero en ocasiones la firma de la sección no dice nada acerca de la titulación del autor. También nos encontramos con que el autor excede sus competencias, como es el caso de la revista "Mujer de hoy", donde una farmacéutica aclara qué información aporta una analítica de sangre, o cómo preparar correctamente un biberón (Anexo $1)$.

\section{CONCLUSIONES}

De la elaboración del presente estudio se desprende que el impacto de la profesión enfermera en nuestra sociedad es insignificante. Muestra de ello es la ausencia de artículos de difusión popular avalados por enfermeras, - tanto en la prensa escrita como en la digital -, campo en el que sí ocupan posiciones destacadas otros profesionales sanitarios (médicos, farmacéuticos...)

Sí hay artículos firmados por enfermeras en las páginas especializadas de nuestra profesión. Se trata de monográficos de "autoformación" y "autoreciclaje" hechos por y para enfermeras, que no llegan al público en general y alcanzan una menor difusión.

Sobre la visión que la sociedad tiene de la enfermería, vista a través de su literatura contemporánea, se concluye que el rol de cuidadora sigue siendo vinculado a la mujer, pero desde una perspectiva tradicional y romántica de la profesión.

Punto a destacar es la visión que la televisión, como medio de masas, ofrece de nuestra profesión. Tanto en anuncios como en series televisivas ("Cruz y Raya", "El show de Benny Hill", "Médico de familia"...), se da una imagen de la 
profesión que más responde al mito erótico, - basándonos principalmente en el atuendo -, secretaria del médico, - atendiendo aquí a las funciones que se le atribuyen -, que a la simple realidad.

Añadimos, a título personal, que valoramos en su justa medida la importante labor llevada a cabo por las páginas de enfermería para el desarrollo de la profesión. Nos preocupa, no obstante, que la sociedad no sea consciente del reconocimiento y el lugar que, como colectivo, estamos reclamando.

No pretendemos con nuestro estudio criticar la labor educativa llevada a cabo por otros profesionales sanitarios. No es a ellos a quienes queremos tachar de intrusistas. Es a nosotras, como enfermeras, a quienes lanzamos una llamada a la reflexión sobre nuestro papel en la sociedad y la medida en que somos responsables de ello, permitiendo como colectivo que se frivolice sobre nuestra profesión y que otros desempeñen labores educativas que son nuestras.

\section{BIBLIOGRAFÍA}

- Aurel J. M. (1998) El clan del Oso Cavernario Maeva-Lasser; Madrid.

- Ondaatje M. (1995) El paciente inglés. Plaza \& Janés; Barcelona.

- Rubio C. ¿Cómo preparo correctamente el biberón? Mujer hoy, del 10 al 16 de julio de 2004; Tu farmacia

- www. hotmail.com

- www.terra.es

- www.lycos.com

- www.saludalia.com
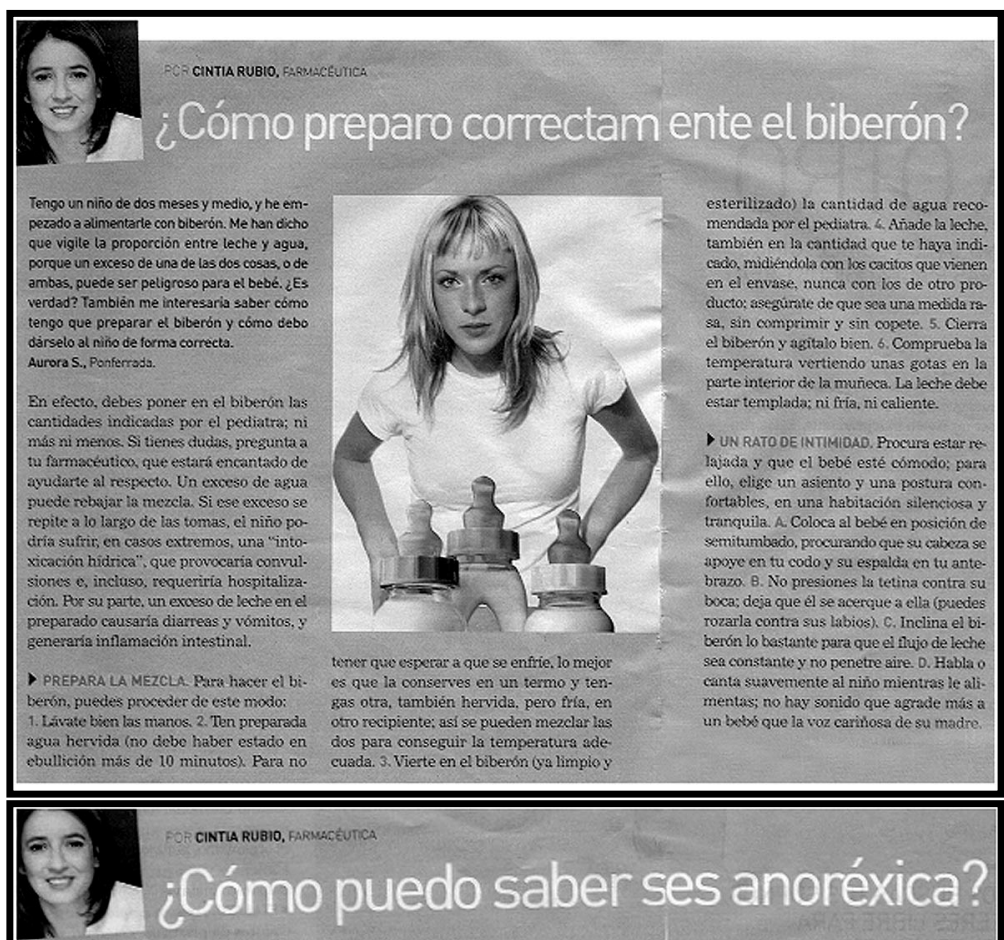

Mi hija come muy poco y está adelgazando a ojos vistas, El aro día compró laxantes. ¿Podría tener anorexis? ¿Qub sintomas debo vigilar? Piedad L., Masnid.

Aunque la compra de laxantes $y$ la pérdida de peso pueden hacer persar en una anorexia nerviast, no son, por si solas, pruebas concluyentes de que tu hija padezca cse trastoma

- ZQUÉ LE OCURRE? Bsta relación mís completa de signos y sintomas pucde ayu. darte a valorar mejor la situación:

darte a valorar mejor la situacion: gue deberia para su edad y altura, y siente que deberia para su edad y altura, y siente pánico ante la idica de en forciar. De hecho, tiene una imagen corporal distorsion. y se ve gruesa a pesar de su delgadez. - Leva tres meses o más sin tener la mens. truactón o ésta no se inicia cusndo debería - So valora en función de su imagen y peso

- Realira ejercicio, pero de una forma com-

pulsiva.
- Utiliza diuréticos y laxantes e incluso vomita, con el objetivo de perder pesa - Como consecuencia de la desnutrición puede padceer sintomas como: constante

\section{CUIDA TU PIEIL}

\section{¿CÓMO HAY QUE CURAR LAS AMPOLLAS?}

$\rightarrow$ Una ampolla es una lesión de la piel que. generalmente se llena de agua Se produce cuando las manos o los pies frotan contra algo constantemente lcomo. por ejemplo. cuando se usa una herramienta durante mucho tiempo o se estrenan botas o zapatos nuevos].

$\rightarrow$ Si la ampolla no se ha roto, déjala estar En cambio, si una vez rota no eliminas la pielde la ampolla, ésta puede crear un entorno ideal para que proliferen los gérmenes bajo ella y para que a quemadura se infecte.

$\rightarrow$ Por eso. cuando esté rota. elimina la piel suelta con mucho cuidado y con ayuda de unas ijeritas, y luego trata la quemadura con una crema apropiada y cúbrela como te indique el médico o el farmacéutico. 